\title{
Bus-Styling Appraisement Research Using Extension Theory-Based on Artificial Neural Network
}

\author{
Yu-Zhou Li ${ }^{*}, 1,2$ and Xia-Mei Tan ${ }^{1,2}$ \\ ${ }^{1}$ Faculty of Electromechanical Engineering, Guangdong University of Technology, 510006, China \\ ${ }^{2}$ Key Laboratory of Innovation Method and Decision Management System of Guangdong Province, 510006, China
}

\begin{abstract}
Automotive body styling appraisement is very important for body styling design. Because there is not tangible standard at the structure ascertaining of artificial neural network(ANN) and improvement of stability is needed for ANN inside black box characteristic, a bus-styling appraisement method using extension theory-based artificial neural network is presented. The key techniques of quasi-three-dimension bus-styling appraisement are investigated, including the idea and process of quasi-three-dimension bus-styling appraisement and the designing and training of extension theory-based artificial neural network model. Moreover, an expert software is developed to appraise bus styling. The effectiveness of the software is finally verified by a practical bus-styling task.
\end{abstract}

Keywords: Artificial neural network, bus-styling appraisement, extension theory.

\section{INTRODUCTION}

Traditional body styling appraisement is base on the explicit expert system that in according to the appraisement and score datum of all kinds vehicle category mine and conclude the experience of specific crowd or experts by the knowledge engineering method of expert system in artificial intelligence field to express the knowledge, experience and rules such as the form "if...then" [1]. However, for this traditional expert system there lies some limitations. At first human has a lot of knowledge than can not be expressed by formulas or expression "if .. then", so this will induce some lost or aberrancy information. Secondly, so many rules in knowledge repository may induce the conflicts of system reasoning process. So some researchers try to introduce fuzzy rules to improve the appraisement method of body styling, but the effect is not good [2]. In addition, for the tradition expert system there is absent of self-study ability and system has no self-study mechanism, so revising repository and supplying knowledge to repository need artificially mode.

For artificial neural network (ANN) with the ability of storing and using experience knowledge and with the good characteristics of self-adaptive, self-study, parallel processing, non-linear processing, fault tolerance and reasoning, so ANN can be used to treat with the body styling appraisement related to causality and imprecise knowledge with conflicts and mistakes [3-12]. And for ANN, there are is tangible standard at the structure ascertaining of artificial neural network and improvement of stability is needed for ANN inside black box characteristic. Extension theory has the advantages to describe the things using basic-element Extension set [13-15], can express complicated datum and resolve the problem, so if integrating the advantages of ANN and extension theory maybe clearly and formally describe the whole process, and deal with the high coupling and nonlinear problem.

BP network and RBF network are the popular artificial neural networks used. BP network has the characters such as complicated structure, large computing information, slow astringency and easily getting into local optimization point. But RBF network has the characters such as simple structure, randomly approaching any nonlinear mapping function, rapid astringency, using any kind of optimization arithmetic to search optimization value and avoiding to get into local optimization point. So in this paper the extension theorybased RBF artificial neural network is used to appraise the bus body styling.

\section{THE BASIC MENTALITY OF QUASI-THREE- DIMENSION BUS-STYLING APPRAISEMENT}

For appraising the automotive body styling if the practicality, 3-dimentions practicality and wire frame blueprint could be appraised may be ideal. And for the characters of artificial neural network, there is better recognition efficiency when ANN is used into intersecting feature recognition and incomplete feature recognition, so some experts have tried to introduce ANN into 3-dimention feature recognition field [16]. Comparing with 2-dimention problem, the difficulty of appraising 3-dimention bus-styling using ANN firstly is shown that it is deeply limited from computer hardware and software because of the information greatly increasing from graphic or image data. Secondly the difficulty is shown that it is very difficult to acquire a great deal of samples of 3-dimention bus-styling. So in this paper the technology of quasi-three-dimension bus-styling 


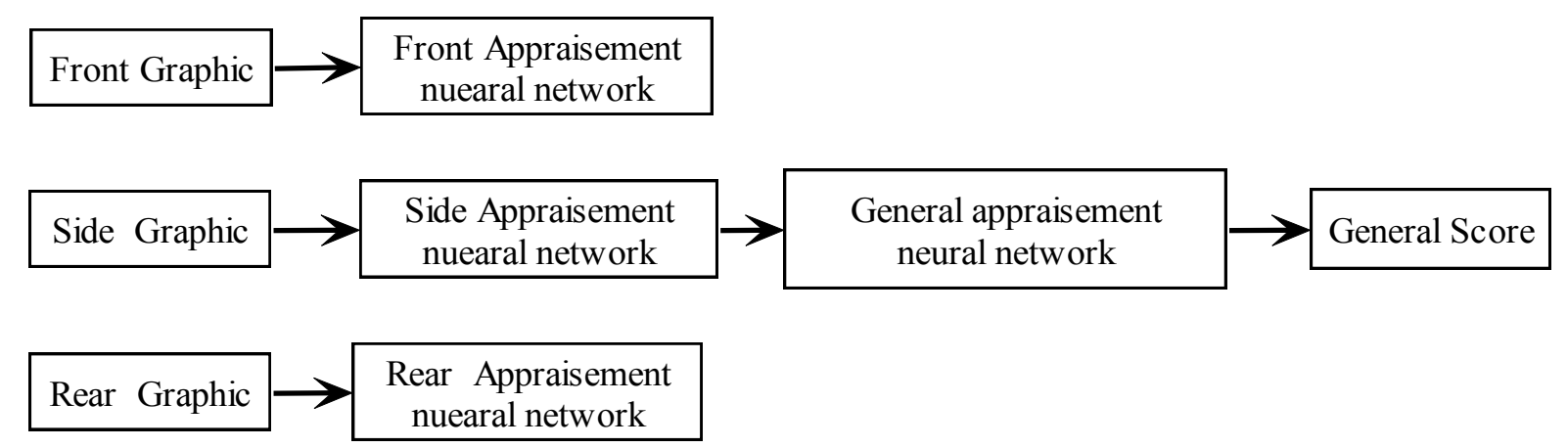

Fig. (1). ANN structure of quasi-three-dimension bus-styling appraisement.

appraisement based on which the features of some key 2dimention image is distilled by ANN is carried out.

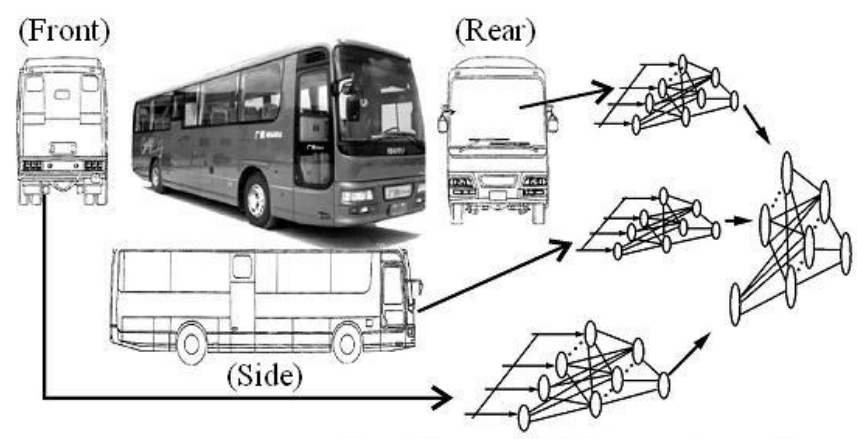

Input Layer Mid-Layer Output Layer

Fig. (2). Structure of ANN model.

Currently in 3-dimention image processing field transforming 3-dimention image into 2-dimention image is processed by nonlinear mapping peculiarity [17]. Bus body is mainly made up of front wall assembly, rear wall assembly and side wall assembly. These three parts are relatively independent, and are almost orthogonal at geometry. As result, the process that quasi-three-dimension bus-styling is made up of these three part 2-dimention graphics is fitted in fact. In this paper the input sample of ANN is the plane wire frame view of bus-styling [18], and the expert appraisement of sample styling is the ideal output of ANN. Then the ANN is trained and the trained ANN of quasi-three-dimension bus-styling is used to appraise and forecast any type bus. Fig. (1) is the ANN structure of quasithree-dimension bus-styling appraisement, and Fig. (2) is the structure of ANN model. Because the fringe of image which is the relative stable information in image is effected relatively less by outer conditions, pretreatment must be done for the 2-dimention graphic of sample data and the distilled main feature line that is made up of wire frame view is appointed to the input data of ANN. In this paper inhibitory interaction principle is used to distill the fringe of image, and this method not only can effectively distill the fringe but also ensure that the distilled fringe is not shifted to the other place and overcome the insufficiency in distilling the fringe feature by common method. In addition the arithmetic is simple. So the method that distilling fringe is used to distill the fringe in real time [19].

\section{THE EXTENSION THEORY-BASED RBF NEURAL} NETWORK

\subsection{RBF Neural Network}

RBF neural network is made up of input layer, hidden layer and output layer. The transfer function need not any transformation., and it can be expressed to ; Hidden layer is made up of a group of radial basis function, and the center of radial basis function and extended parameter are the parameters related with every hidden layer node. Radial basis function has many types such as Gaussian basis function, multi-quadratic basis function, inverse multiquadratic basis function and so on. If the basis function is the Gaussian basis function, then the transfer function of hidden layer is shown as the expression (1).

$F_{k}(x)=\exp \left(-\frac{\left\|x-c_{k}\right\|^{2}}{2 \sigma_{k}^{2}}\right)$

$\mathrm{c}_{k}$ is the center vector of k'th Gaussian function, and is the weight between input layer and hidden layer. $\sigma_{k}$ is the width of $k^{\prime}$ th Gaussian function. $\|\boldsymbol{\|}\|$ is the 2-norm and is expressed as the Euclidean distance between $x$ and $\mathrm{c}_{k}$.

The output of output is acquired from the weighted summing of output data of hidden layer node, and the transfer function is shown as expression (2).

$y j=\sum_{k=1}^{p} w_{k j} F_{k}$

$w_{k j}$ is the weight between $\mathrm{k}$ node of hidden layer and $j$ node of output layer, $F_{k}(x)$ is the $\mathrm{k}$ node output of hidden layer, $y_{i}$ is the $j$ node output of output layer.

The study rule used in RBF ANN is two-step study rule. Firstly the node number and the center and width of hidden layer are ascertained by K-means arithmetic. And secondly the gradient descent method is used to train and ascertain the link weight of hidden layer and output layer.

The study rule used in RBF ANN is two-step study rule. Firstly the node number and the center and width of hidden 
layer are ascertained by K-means arithmetic. And secondly the gradient descent method is used to train and ascertain the link weight of hidden layer and output layer.

\subsection{The Extension Theory-Based RBF Neural Network}

The extension theory-based RBF neural network is a feed-forward neural network and study arithmetic without tutor and has only one hidden layer. In this paper extension transformation is used to dynamically adjust the node number of hidden layer, that is the system adjust the parameters or structure of system in according to the some rules of sample data so as to express the inherent feature of outer input. During the training process of extension theory based RBF neural network, firstly using multi-dimension matter-element model describe every input sample, and then using combinative property of extension transformation through decreasing transformation, and extending and reducing transformation realize the normalization; secondly, using multi-dimension matter-element model describe the center vector and set distance parameter threshold, at the same time the first clustering center is acquired through the copying transformation of the first sample, and then the initiative transformation on center matter-element objective is carried into execution to induce the conducting transformation of corresponding feature value. Thirdly, after extend the distance definition of extension theory to ndimension matter-element, the extending distance equation is acquired and according to the equation computer the minimum extension distance of all samples and existed centers, then adjust the center and weight value by using replacing transformation according to the different conditions until all clustering process is converged. Fourthly, the width is calculated and LMS arithmetic is used to adjust the weights of hidden layer and output layer. The flow chart is shown as Fig. (3).

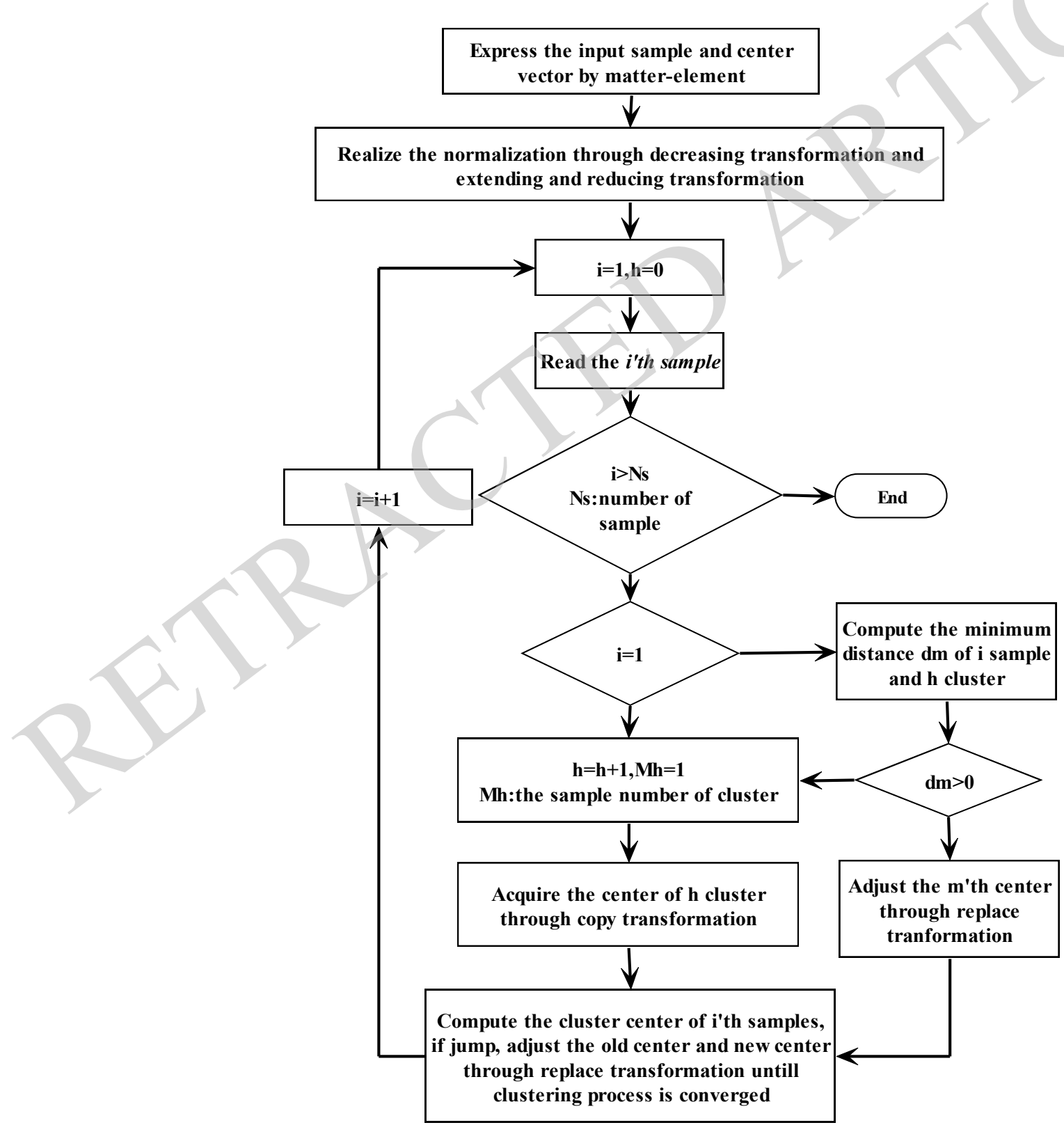

Fig. (3). Flow chart of extension clustering process. 


\section{THE DEVELOPMENT OF APPRAISEMENT SOFTWARE}

For the actual users of the software, based on the developed ANN of bus-styling appraisement, the visualization developed tool to complete the bus-styling appraisement software. The main part of software is made up of proscenium visualization part and backstage ANN part. The backstage ANN program is built on the Matlab platform with ANN module and image process module, and because the Matlab platform has strong ability of numerical treatment and computing, the software and program has good characters with simpleness, easily transplanting and extending, high reliability and reducing the direct operation of hardware. The proscenium visualization part use the ActiveX technology to realize the linkage between backstage ANN part and sample database, and can dynamically revise the basic parameters of ANN and database so as to let users complete the work which load training samples, initialize weight, train neural network, load test samples and appraise test samples.

\section{THE APPLICATION OF BUS-STYLING APPRAISEMENT SOFTWARE}

When redesign the bus-styling, the corporation designers mainly redesign the grille styling and use the appraisement expert system based on extension theory-based RBF neural network to appraise amending redesign of the bus-styling. Figs. $(\mathbf{4}, \mathbf{5})$ is the bus-styling before redesigning and after redesigning. Tables $\mathbf{1}$ and $\mathbf{2}$ show the scores of bus-styling. From the appraisement result, the score of newer styling is higher than older styling. In addition, the score of side wall assembly of newer styling is highest, and indirectly is affirmed that the styling is successful. Through analyzing and comparing, the corporation put the newer styling into production, and the market reaction is good.

\section{CONCLUSION}

In this paper the method of the extension theory-based RBF neural network is applied into the bus-styling appraisement. In addition, the intelligent expert system of bus-styling appraisement is developed and applied into the
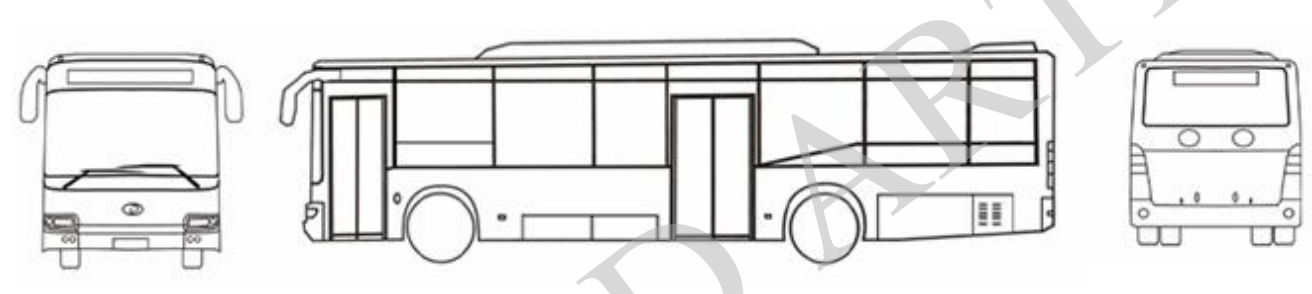

Fig. (4). Bus-styling before redesigning.
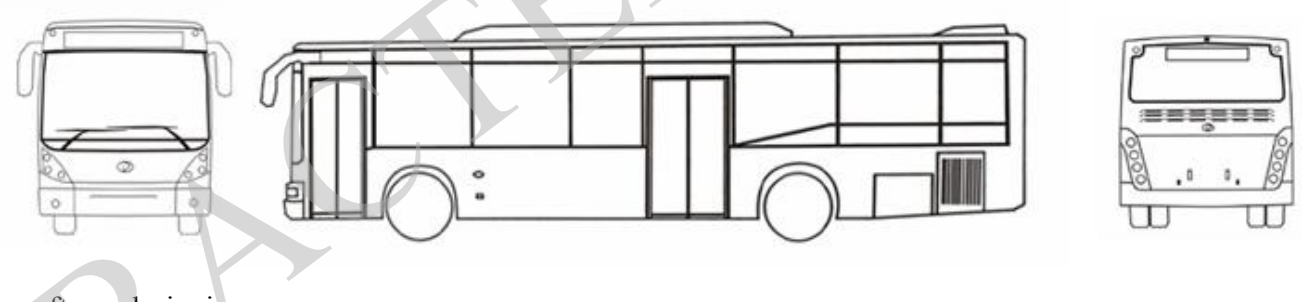

Fig. (5). Bus-styling after redesigning.

Table 1. The score of bus-styling before redesigning.

\begin{tabular}{|c|c|c|c|c|c|c|}
\hline & Under 30 Years Old & 31-40 Years Old & 41-50 Years Old & 51-60 Years Old & Domestic Expert & Abroad Expert \\
\hline \hline Front & 75.1 & 75.6 & 75 & 74.9 & 74.9 & 74.9 \\
\hline Side & 67.8 & 70.9 & 60 & 72.3 & 65.8 & 74.2 \\
\hline Rear & 75.2 & 75.1 & 7.5 & 74.9 & 75 & 74.9 \\
\hline General Score & 71.7 & 73.3 & 69.4 & 74.2 & 70.9 & 75.7 \\
\hline
\end{tabular}

Table 2. The score of bus-styling after redesigning.

\begin{tabular}{|c|c|c|c|c|c|c|}
\hline & Under 30 Years Old & 31-40 Years Old & 41-50 Years Old & 51-60 Years Old & Domestic Expert & Abroad Expert \\
\hline \hline Front & 80.1 & 80.6 & 80.3 & 80.3 & 78.9 & 79.4 \\
\hline Side & 84.5 & 81.1 & 81.2 & 81.6 & 80.1 & 80.2 \\
\hline Rear & 82.6 & 82.3 & 80.6 & 81.2 & 80.2 & 80.3 \\
\hline General Score & 81.8 & 80.5 & 82 & 81.1 & 80.5 & 80.2 \\
\hline
\end{tabular}


bus-styling redesigning mission of corporation. The good market reaction is shown the feasibility of expert system based on the extension theory-based RBF neural network.

\section{CONFLICT OF INTEREST}

The authors confirm that this article content has no conflict of interest.

\section{ACKNOWLEDGEMENTS}

The paper is finished under support of the project of the department of education of Guangdong Province -the high level natural foundation of Guangdong high colleges (LYM10072), Opening Specific project of key Laboratory of Innovation Method and Decision Management System of Guangdong province, China (2011A060901001-10D) and national natural scientific research starting foundation project of School of Electromechanical of Guangdong University of Technology. In addition, this work was supported too by the Innovation Methods Specific Projects of Science and Technology Ministry, China (No. 2011IM020300), the Industry-Academia-research Cooperation Foundation of Guangdong Province, China (No.2011A91000040), and the Innovation Methods Specific Projects of Guangdong Province, China (No. 2011B061100001). Thank for the support of the all above foundations.

\section{REFERENCES}

[1] X. Huang, Automotive aerodynamic and body styling, Beijing: People Traffic Press, 2000.

[2] X. He, "Fuzzy evaluation for body exterior styling of commercial vehicle", Automobil. Sci. Tech., vol. 5, pp. 25-26, 2005.
[3] S. Haykin, Principle of artificial neural network, Beijing: Mechanical Industry Press, 2004.

[4] X. Hu, "Aesthetics feature identification and modification for product molding based on neural network", J. Wuhan Univ, Tech: Inform. Manag. Eng., vol. 26, pp. 21-24, 2004.

[5] X. Huang, C. Xie, Y. Xie, "Preliminary study of ANN based aesthetic evaluation for automobile body styling", China Mech. Eng., vol. 13, pp.420-423, 2002.

[6] E. Robinson, V.F. Giles, "System for evaluating hyperdocuments using a trained artificial neural network", U.S. Pantent 12,984,594, November 26, 2013.

[7] A.R. Marcantonio, "Artificial neural network (ANN) classifier apparatus for selecting related computer routines and methods", U.S. Pantent 07,899,808, December 26, 1992

[8] S.M. Al-Fattah, "Artificial neural network models for determining relative permeability of hydrocarbon reservoirs", PCT 2008, 010285, March 12, 2009.

[9] C.L. Black, "Method and system for training an artificial neural network", U.S. Pantent 09,282,392, July 31, 2001

[10] B.D. Kulkarni, "Performance of artificial neural network models in the presence of instrumental noise and measurement errors", U.S. Patent 10,112,069, December 25, 2007.

[11] L.D. Curt, "Systems and methods for creating an artificial neural network", PCT 2008,010285, October 26, 2007.

[12] J.C. Cummins, "Current transformer saturation correction using artificial neural networks", U.S. Patent, 09,275,388, June 12, 2001.

[13] W. Cai, Preliminary Extension Logic, Beijing: Science Press, 2003.

[14] C. Yang, and W. Cai, Extension Engineering, Beijing: Science Press, 2007.

[15] Y. Zhao, Extension Design, Beijing: Science Press 2010.

[16] J.L. Hwang, M. R. Henderson, "Applying the perception to threedimensional feature recognition", Design Manufact., vol. 2, pp. $178-198,1992$.

[17] H. Chen, W. Jin, N. Zhang, "A restoration method for 3D image of the wide-field microscope based on the network", Acta Photonica Sinica, vol. 35, no. 6, pp. 473-476, 2006.

[18] Y. Ou, Z. Yuan, "Neural network applied in two-dimension image recognition”, China Measure. Tech., vol. 35, pp. 111-113, 2006.

[19] H. Wang, Y. Li, "Application of lateral inhibition models in color image edge enhancement”, Comput. Eng. Appl., vol. 26, pp. 55-57, 2003

\footnotetext{
Received: January 8, 2015

This is an open access article licensed under the terms of the Creative Commons Attribution Non-Commercial License (http://creativecommons.org/licenses/by-nc/3.0/)
} which permits unrestricted, non-commercial use, distribution and reproduction in any medium, provided the work is properly cited. 